\title{
SOIL SAMPLING STUDIES FOR ESTIMATION OF WEED SEEDBANKS
}

\author{
A. RAHMAN, T.K. JAMES, J.E. WALLER \\ and N. GRBAVAC ${ }^{1}$ \\ AgResearch, Ruakura Research Centre, Private Bag 3123, Hamilton \\ ${ }^{1}$ MAFQual, Official Seed Testing Station, P O Box 609, Palmerston North
}

\begin{abstract}
Studies were conducted during 1996-97 to develop guidelines for soil sampling to best estimate the weed seedbank. Results based on samplings from 15 arable sites showed large within site variations. For predicting a given seed population with some accuracy, either the species has to be present in large numbers $\left(>1000 / \mathrm{m}^{2}\right)$ and/or large numbers of soil cores need to be taken. Comparison of results from $25 \mathrm{~mm}$ and $75 \mathrm{~mm}$ diameter cores (from 5 arable sites), showed that collecting the same quantity of soil with a greater number of smaller cores would give better estimates. For practical purposes, approximately 25 cores, each $25 \mathrm{~mm}$ diameter, may provide a sufficient size sample for fields of annual crops such as maize. Keywords: Weed seedbank, soil seed reservoir, soil sampling, seed extraction, weed seeds
\end{abstract}

\section{INTRODUCTION}

Annual weed populations are established every year because of persistent seedbanks in arable soils. As most of the weed species in arable cropping systems are annuals, some knowledge of the seedbank may be a good starting point for an integrated weed management programme (Forcella 1993). Studies on weed seedbanks have demonstrated large variability in both density and composition between samples taken from the same site (Benoit et al. 1992; Rahman et al. 1996). This is directly related to the problematic nature of seedbanks in cropping systems, such as clustered seed patterns and skewed frequency distribution of most species (Bigwood and Inouye 1988; Dessaintet al. 1990; Wilson and Aebischer 1995). The consequence of clustered distribution of weed seed in the soil is the negative binomial or Poisson distribution often observed with many species (Benoit et al. 1989; Chauvel et al. 1989).

Weed seedbank studies often suffer from major methodological inadequacies such as absence of appropriate statistical data analysis and low sampling intensity (Benoit $e t$ al. 1992). Two important questions arise in relation to sampling a weed seedbank. How many samples are required to describe an arable seedbank and which method of seed enumeration is best suited for studying seed population dynamics in the soil? Our recent studies aimed to evaluate the seed enumeration methods for estimating the weed seedbank have shed some light on the second question (Rahman et al. 1995; 1996). The work reported in this paper was designed to evaluate the relationship between the number of soil samples and the number and density of weed seeds in arable soils. The effect of the size of individual samples on quantifying this relationship was also investigated in a related experiment.

\section{MATERIALS AND METHODS}

Fifteen sites from Waikato and Bay of Plenty which had a history of maize production were selected for this study. Thirty soil cores, $25 \mathrm{~mm}$ diameter, were taken from each site to a depth of $100 \mathrm{~mm}$. The cores were taken at regular intervals along transects, with the number of transects and the number of cores per transect being determined by the shape of the site. Thus, long narrow sites had only two transects and 15 cores were taken from 
each while, for square fields, six cores were taken from each of five transects. Each soil core was individually bagged and numbered. Weed seeds were extracted and enumerated from each core by the MAFQual Official Seed Testing Station using the method previously described (Rahman et al. 1995). Briefly, individual cores were washed through a fine mesh to remove soil particles. The remainder was air dried and then passed through a descending series of sieves. Whole seeds from each sieving were extracted by hand, identified and counted. Seed viability was determined by crushing the seed and inspecting the endosperm, with only those seeds exhibiting white healthy endosperm included in the counts.

In a related study conducted at five of the above sites, soil cores of two different diameters $(25 \mathrm{~mm}$ and $75 \mathrm{~mm})$ were also collected from each of the 30 sampling points. Weed seed in these samples were enumerated using the seedling emergence method previously described (Rahmanet al. 1995). Briefly, each sample was spread thinly onto porous cloth material over wet vermiculite. This was maintained in the glasshouse for 30 days when the emerged seedlings were identified and counted. This incubation process was repeated once more and the seed counts added to the first.

All the data were analysed using regression type methods. The data points in Figs. 1 and 3 were obtained by calculating means and standard deviations from the 30 cores for all site and species combinations, and the variances are presented in Fig. 3. The solid lines provided are splines fitted by the Bayesian smoothing program FLEXI (Upsdell 1994), and the broken lines are the $95 \%$ confidence interval for the line. The lines in Fig. 2 were calculated using standard deviations predicted from the spline in Fig. 1.

\section{RESULTS AND DISCUSSION}

Using the seed extraction method, about 40 weed species in total were recorded in the soil samples collected from the 15 field sites. However, some of the species had only one seed present in the composite sample of 30 cores at some sites. Interestingly no single weed species was common to all 15 sites. The highest occurrence was for white clover (Trifolium repens) and toad rush (Juncus bufonius), both of which were recorded on 14 sites. Neither of these weeds are of agronomic or economic significance in maize production (Rahman 1988). Two grass weeds, summer grass (Digitaria sanguinalis) and smooth witchgrass (Panicum dichotomiflorum), along with fathen (Chenopodium album) were each recorded on 12 sites and black nightshade (Solanum nigrum) on 10 sites.

All the weed species encountered at these sites have been divided into four groups which are listed along with their total seed numbers in Table 1. Summer grasses consisted principally of three annual species viz., smooth witchgrass, summer grass and barnyard grass (Echinochloa crus-galli). Toad rush was included in the group of winter grasses along with annual poa (Роа аппиа). The summer broadleaf group comprised mainly Amaranthus spp; fathen, black nightshade, willow weed (Polygonum persicaria) and on some sites thorn apple (Datura stramonium). The last group, the winter broadleaf, included chickweed (Stellaria media), twin cress (Coronopus didymus), spurrey (Spergula arvensis) and docks (Rumex spp.).

Some obvious differences were noted in the weed seed density between the sites which appeared to be at least partially related to the soil type. The first 8 sites in Table 1 were sandy to sandy loam in texture, while sites 9 to 12 were silt loams. Site 13 was a heavy clay soil and seeds of only 7 weed species were recorded. Also this was the only site with no white clover or toad rush seed. The last two sites were recently developed peat and had the highest weed seed counts. Here the winter grass component comprised $88 \%$ and $95 \%$ of toad rush seed which would not be very competitive in a maize crop. However, the very high number of winter broadleaf weeds could prove very competitive because it included docks, buttercups (Ranunculus spp.) and pennyroyal (Mentha pulegium ) which are difficult to control, and an effective post-ermergence herbicide would need to be included in the weed management programme for such sites (Rahman 1988).

TABLE 1: Number of seeds /30 soil cores ${ }^{1}$ estimated by weed seed enumeration method in soil samples collected from 15 field sites in Waikato/Bay of 
Plenty.

\begin{tabular}{rrrrrr}
\hline Site & \multicolumn{4}{c}{ Groupings of weed species } \\
& $\begin{array}{c}\text { Summer } \\
\text { grasses }\end{array}$ & $\begin{array}{c}\text { Winter } \\
\text { grasses }\end{array}$ & $\begin{array}{c}\text { Summer } \\
\text { broadleaf }\end{array}$ & $\begin{array}{c}\text { Winter } \\
\text { broadleaf }\end{array}$ & $\begin{array}{r}\text { Total } \\
\text { seed }\end{array}$ \\
\hline 1 & 292 & 56 & 16 & 33 & 397 \\
2 & 54 & 22 & 71 & 20 & 167 \\
3 & 137 & 6 & 27 & 3 & 173 \\
4 & 80 & 111 & 13 & 45 & 249 \\
5 & 1 & 183 & 11 & 49 & 244 \\
6 & 18 & 67 & 40 & 35 & 160 \\
7 & 74 & 78 & 37 & 8 & 197 \\
8 & 29 & 47 & 15 & 25 & 116 \\
9 & 7 & 11 & 60 & 16 & 94 \\
10 & 10 & 1 & 46 & 8 & 65 \\
11 & 14 & 2 & 37 & 6 & 59 \\
12 & 3 & 1 & 44 & 6 & 54 \\
13 & 10 & 0 & 123 & 1 & 134 \\
14 & 106 & 3407 & 21 & 117 & 3651 \\
15 & 0 & 1257 & 18 & 229 & 1504 \\
\hline
\end{tabular}

${ }^{1}$ Each core was $25 \mathrm{~mm}$ diam. to a depth of $100 \mathrm{~mm}$ (multiply by 68 to get seeds $/ \mathrm{m}^{2}$ ).

In practice, for offering herbicide advice, it is necessary to deal with individual species rather than coarse groupings. Therefore the variability of individual species has to be investigated. Fig. 1 shows the standard deviation versus the mean of all site and species combinations. This graph is similar in shape to that of Dessaintet al. (1996), and shows increasing variability with increasing seed numbers and this holds for all species. In practice we have no prior knowledge of the number of seeds that will be found at a particular site, but we can use the results of this study to estimate the accuracy of the

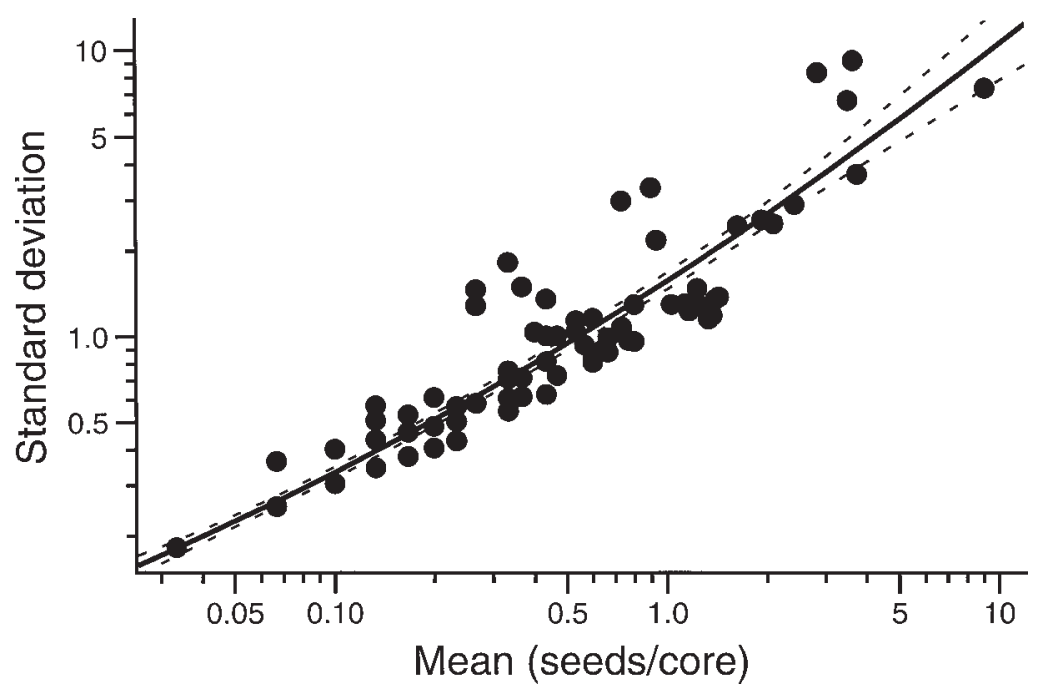

FIGURE 1: Standard deviation versus mean for all weed species found in the 25 mm diam. cores from all 15 sites. 
counts obtained at that site.

The major concerns in estimating seed counts are: (1) overestimating counts of weeds with very low populations and, probably more importantly; (2) underestimating a significant weed population or the likelihood of completely missing an important weed species. Suppose, in the very best scenario, that seed is uniformly distributed around a field. If there are 200 viable seeds of a weed $/ \mathrm{m}^{2}$, then the probability of failing to detect this weed at all, with a sample of 12 cores of $25 \mathrm{~mm}$ diameter (approximately $0.5 \mathrm{~kg}$ dry soil), is 0.30 . If the sample size is increased to 25 cores (approx. $1 \mathrm{~kg}$ dry soil, the maximum size of samples which can be readily handled by the Seed Testing Station), this reduces to a probability of 0.08 .

The relationship betwen means of seed $/ \mathrm{m}^{2}$ and SEM/mean (Fig. 2) suggests that to obtain an accurate estimate of a weed seed population, either the species has to be present in large numbers $\left(>1000 / \mathrm{m}^{2}\right)$ and/or a large number of cores need to be taken. The data calculated in Fig. 2 suggest that 12 cores are insufficient for estimation purposes due to large variance, especially at low seed numbers. Increasing the core numbers to 25 improves the SEM of the estimate by approximately $30 \%$.

When comparing the results from $25 \mathrm{~mm}$ cores with $75 \mathrm{~mm}$ cores in the second study, it was found that the larger cores had lower variability than the smaller cores, as

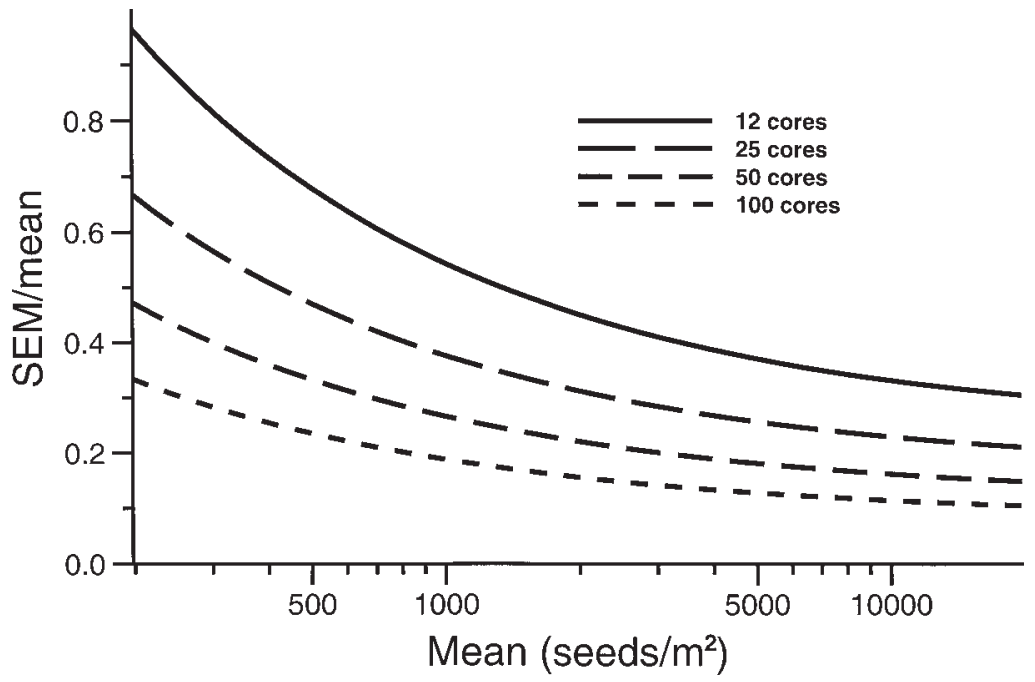

FIGURE 2: The ratio of the standard error of the mean (SEM) to the mean for various seed densities and sample sizes. The standard errors used for the calculations are based on the line in Fig. 1.

would be expected. However, this reduction in variability was not in the same ratio as the volume of soil collected in the different cores (Fig. 3). Taking smaller cores allows a better coverage of the field, thus overcoming much of the problem caused by spatial variability (Rahman et al. 1996). From this it is concluded that it is better to use a smaller size core while keeping the total amount of soil constant.

For accurately estimating the size of the seedbank and/or finding the seed of an important weed species present in low numbers, it would be desirable to obtain a large number of cores, but the cost-benefit ratio also needs to be taken into account. Thus, the determination of the required number of samples must be a compromise between the practical limitations and the precision required. Results of the present study and many 
previous studies have shown a large degree of inherent variation in the weed seedbank, sometimes over small distances. There is also the limitation of the maximum size of an individual sample that can be readily handled by the laboratory (approx. $1 \mathrm{~kg}$ dry soil). Sophisticated statistical analyses have indicated that hundreds of cores may be necessary to reliably sample seedbanks (Dessaintet al. 1990; 1996). It has been suggested by others (eg. Forcellaet al. 1992), however, that for practical purposes, 10-20 cores, each $50 \mathrm{~mm}$ diameter, are probably sufficient for a single field or management unit. The present study suggests that approximately 25 cores, each $25 \mathrm{~mm}$ diameter, may provide a sufficient size sample for fields of an annual crop such as maize to estimate the density and composition of its seedbank. More samples may be collected to increase the accuracy if the cost is acceptable.

\section{REFERENCES}

Benoit, D.L., Kenkel, N.C. and Cavers, P.B., 1989. Factors influencing the precision of

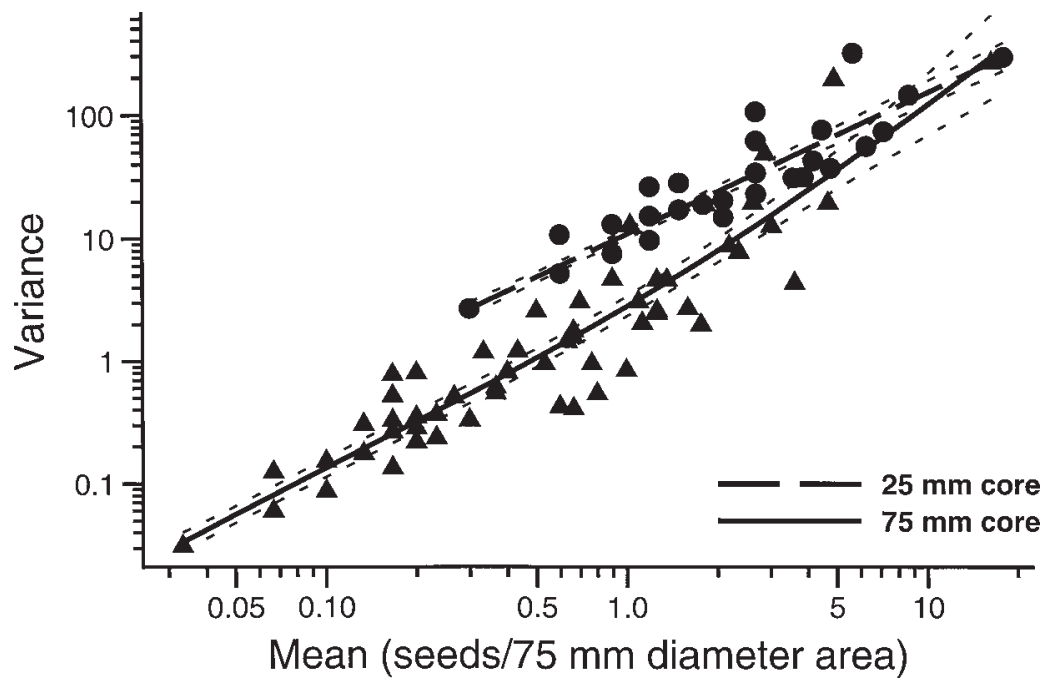

FIGURE 3: Variance versus the mean for two different core sizes $(25$ and $75 \mathrm{~mm}$ diam.), with separate splines fitted. For comparison these counts were adjusted to a common area $(75 \mathrm{~mm}$ diam.) basis.

soil seed bank estimates. Can. J. Bot. 67: 2833-2840.

Benoit, D.L., Derkson, D.A. and Panneton, B., 1992. Innovative approaches to seedbank studies. Weed Sci. 40: 660-669.

Bigwood, D.W. and Inouye, D.W., 1988. Spatial pattern analysis of seedbanks: an improved method and optimised sampling. Ecol. 69: 497-507.

Chauvell, B., Gasquez, J. and Darmency, H., 1989. Changes of weed seedbank parameters according to species, time and environment. Weed Res. 29: 213-219.

Dessaint, F., Barralis, G., Caixinhas, M.L., Post, B.J. and Zanin, G., 1990. EWRS collaborative study of seedbank estimation: 1 . Studies of the relation between the mean and the variance with sampling procedure. Weed Res. 30: 421-429.

Dessaint, F., Barralis, G., Caixinhas, M.L., Major, J.-P., Recasens, J. and Zanin, G., 1996. Precision of soil seedbank sampling: how many soil cores?Weed Res. 36: 143151.

Forcella, F., Wilson, R.G., Rener, K.A., Dekker, J., Harvey, R.J., Alm, D.A., Buhler, D.D. and Cardina, J., 1992. Weed seedbanks of the U.S. Corn Belt: Magnitude, 
variation, emergence and application. Weed Sci. 40: 636-644.

Forcella, F., 1993. Prediction of weed densities from the soil seed reservoir. Proc. Int. Symp. Indian Soc. of Weed Sci. , Hissar, Nov. 1993, 1: 53-56.

Rahman, A., 1988. Recent major problems of weed control in maize in New Zealand. Med. Fac. Landbouww. Rijksuniv. Gent 53: 1335-13440.

Rahman, A., James, T.K., Grbavac, N. and Mellsop, J., 1995. Evaluation of two methods for enumerating the soil weed seedbank. Proc. 48th N.Z. Plant Prot. Conf.: 175180.

Rahman, A., James, T.K., Grbavac, N. and Mellsop, J., 1996. Spatial distribution of weed seedbank in maize cropping fields. Proc. 49th N.Z. Plant Prot. Conf.: 291295.

Upsdell, M.P., 1994. Bayesian smoothers as an extension of non-linear regression.N.Z. Statistician 29: 66-81.

Wilson, P.J. and Aebischer, N.J., 1995. The distribution of dicotyledonous arable weeds in relation to distance from the field edge. J. Appl. Ecol. 32: 295-310. 